\title{
A Bilingualism Journey of a Libyan Bilingual Child in Australia: the fossilization of the first language and the acquisition of the second language
}

\author{
Hamza Mohammed Abd Muftah \\ (English Department, Faculty of Education/Abee Essa, Alzawia University, Libya)
}

\begin{abstract}
This case study investigated the relationship between specific socio-psychological factors and the development and maintenance of two languages (Arabic and English). Especially, The study examined the influence of bilingual children's families, monolingual schools, the second language society, group culture identity, the ethnic group and children' attitudes on the development and maintenance of two languages. The study looked at how such factors could impact on acquiring, developing and fossilizing Arabic and English languages. The current research was basically undertaken on a Libyan child who has lived in Australia for 4 years. The researcher used semi-structured interviews and observations to gather data about the topic. The results demonstrated that these socio-psychological factors have a great impact on developing the second language and impeding the native one.
\end{abstract}

Key words: bilingualism, biliteracy, ethnic group, fossilization, heritage language maintenance, second language acquisition, social identity.

\section{Introduction}

With globalisation in the 20th and 21st century, bilingualism and multilingualism have widely increased. According to The reference [1], it is estimated that two-thirds of the worldwide population became bilinguals [2]. Such a phenomenon has been influenced by many factors which play a significant role in supporting or impeding bilingual and biliteracy development of bilingual children. Consequently,. This case study looked at the impact of a number of socio-psychological factors (bilingual children's families, monolingual schools, the second language society, group culture identity, the ethnic group and children' attitudes) on the development of two languages experienced by a Libyan bilingual child. The case study investigated how such elements influence the L2 acquisition and the heritage language maintenance. Particularly, the study attempted to form an in-depth understanding of the mechanism of these sociopsychological in developing or impeding the two languages acquired and learnt by the participant.

\subsection{Literature review}

Bilingualism is defined as the regular use of languages rather than fluency [3]. In addition, bilinguals are seen as "those who use two or more languages (or dialects) in their everyday lives" [4]. Researchers believe that bilingualism is typically influenced by a set of socio-psychological factors that can develop or hinder such a process. For instance, the reference [2] found out that as a result of attending classes in a heritage language school and parents' efforts, a focal Korean-English bilingual child was successfully able to develop good levels of the native language literacy even though he had been born and had live in the UK. It was also reported that Some strategies used by parents (e.g. using the heritage language at the home) can provide children with access to the native culture and preserve the mother language [5]. Another indispensible factor is codeswitching which is seen as a significant apparatus in developing the second language and maintaining the heritage one [6].

Additionally, the reference [4] stated that schooling education can play an indispensable part in producing bilingual children. The reference [7] points out that effective schools and classrooms can be a fertile environment for those who want to develop two languages. bilingual negative attitudes towards the heritage and the power of the second language may definitely lead in the lose their the first language and development of the L2 [2]. Hence, many socio-psychological factors might play an effective part in bilingual and billiteracy development among immigrants children. The literature evidently demonstrated that there should be a link between the development of two languages and the socio-psychological variables. Additionally, the literature reported that such variable can influence the linguistic development of the dual language positively or negatively. 


\subsection{Research questions}

This study focuses on eleven year old Libyan-English bilingual child. The study discuss how specific factors (the family, monolingual schools, the second language society, the participant's ethine group, the ethnic culture identity and the child' attitude) affected the bilingual and billiteracy development of two languages experienced by the child. Therefore, the current study will address the following research questions:

Q1. What was the role of the child's family and parents in maintaining the first language (L1) and acquiring the second language (L2)?

Q2. What was the part that school plays in assisting the subject to acquire L2?

Q3. What resources were available for the participant to acquire L2 in the second language community?

Q4. Did cultural identity help the subject to maintain the L1 and was cultural identity an issue in acquiring the L2?

Q5. What is the child's attitude towards the two languages and what part did his attitude play in developing the two languages?

Q6. Did the participant's minority group contribute to the maintains of the first language?

\subsection{Purpose of the study}

The aims in doing this study are:

- To find out how the parents behaviour impacted on the bilingual and biliteracy development of the participant.

- To explore that the role that L2 community played in supporting the child's second language.

- To know if the group cultural identity helped the child in preserving his home language.

- To investigate if the home language plays a role in constructing the participant's ethnic identity.

- To examine the influence of the monolingual school on the participant's second language (L2) development

\section{Research Methods}

This case study was designed to investigate the effect of a number of socio-psychological factors on the development and maintenance of two languages (Arabic and English). This chapter will present the methodological framework of this study, including (1) methodological structure of the study, (2) the settings of the study (5) the subjects and (6) data-collection instruments.

\subsection{The Setting of study}

This study was undertaken in a rural city located in Southern Queensland in Australia. The majority population in this city is Australians and the dominant language is Australian-English. Additionally, a number of multicultural ethnic groups settle in Toowoomba such as the Arabic community, Asian communities, Sudanese community and refugees from African countries. There is a large, prestigious university with a good percentage of Arabic international students. There is an Arabic-Islamic centre in the city. The Arabic community has not long been in the city. There is no Arabic-English bilingual school. The neighbourhood, where Ahmed with his family lives, is mainly families of diverse cultural and linguistic background.

\subsection{Participants}

The main participant is a 10-years Libyan child who has lived in Australia for 4 years (see TABLE I). He was born in Libya and lived there for around six years. The child is from a Libyan linguistic minority. When the participant came to Australia, his English was poor. He has been now living in Australia for five years. During that time, the child increasingly developed his English. Within the first two years of his residence in Australia, he became an English-Arabic bilingual whose English (L2) took precedence on Arabic (L1). He was a pupil at monolingual school at the time of study. The child's parents also took part in this study. The child's father is a PHD student and his mother is a housewife. In addition, the child's siblings (females; the older aged 14 and the younger aged 8) and his parents participated in the study as minor participants (see TABLE I). Both of his sisters were pupils at monolingual school and are Arabic-English bilinguals.

Table 1: Overview of the Participants

\begin{tabular}{|c|c|c|c|c|}
\hline \multicolumn{5}{|c|}{ Participants } \\
\hline Name & Job & Age & Length of residency & Native language \\
\hline Ahmed & Pupil & 10 & 4 & Arabic \\
\hline Name & Mob & Age & Length of residency & Native language \\
\hline Ahmed's father & BHD student & 45 & 4 & Arabic \\
\hline Ahmed's Mother & House wife & 38 & 4 & Arabic \\
\hline
\end{tabular}




\begin{tabular}{|c|c|c|c|c|}
\hline Ahmed's sister 1 & Pupil & 14 & 4 & Arabic \\
\hline Ahmed's sister 2 & Pupil & 8 & 4 & Arabic \\
\hline
\end{tabular}

\subsection{Data Collection Instruments}

\subsubsection{Semi-structured Interview}

A semi-structured interview (SSI) was conducted with both the principle participant and the minor participants by the researcher. A semi-structured interview is a "verbal questionnaire consisting of a series of questions designed to elicit specific answers on the part of respondents" [8]. The SSI consisted of 15 openended questions (see appendix A) created in order to obtain in-depth information about 'a participants' thoughts, beliefs, knowledge, reasoning, motivation and feelings about the topic" [9]. Semi-structured interviews were conducted over a period of three weeks to collect data about the role and influence of the family (particularly parents), school, the second language community and the group-cultural identity on bilingual and biliteracy development of a Libyan child aged 11. The interview was undertaken in English and Arabic. The researcher scenarios used in both Arabic languages to clarify some questions for the participants. The interview was audibly recorded and transcribed to texts.

\subsubsection{Observations of the participant}

The researcher observed the participant during a typical day at school and home. Each observation time resulted in 1-4 hours of continuous observation. Observations took place in October 2011. The participant knows that he is observed by the researcher.

\section{Findings}

This section will provide a description and analysis of data obtained from the semi-structured interview and observations designed to investigate the following research questions:

\section{(Q1. What is the role of the child's family and parents in maintaining the first language (L1) and acquiring the second language (L2)? What sources are available for the participant to maintain the heritage language?)}

The participant's parents were an integral part in his L2 learning as well as academic education. They guided Ahmed (the participant's name) through his study and gave him a boost to be a proficient in English as the only medium of instruction in school. Ahmed's parents tried to balance between Arabic as a key cultural component, and English. However, their apprehension and excessive interest of Ahmed's study led them to give a greater concern to English. Ahmed's father says:

When they arrived in Australia five years ago, they were aware of the importance of maintenance of Arabic as a cultural identity. But, because English was the medium of instruction and English proficiency of Ahmed was poor, they had to give a greater attention to English.

To enable Ahmed to be an English fluent speaker, the family began conversing in English at home. All materials (e.g. stories and cartoons) that they brought to Ahmed were in English. Ahmed' mother indicated that all of these procedures made English abilities surpass his Arabic abilities. Also, she reported that such actions made Ahmed lose many words and stop learning or/and acquiring new ones. Through the interview with his siblings (Elham and Aisha), it was discovered that Ahmed was preferring English in communication with them. In addition, during the observation hours at his home, the researcher noticed that Ahmed was heavily interested in using English for chatting with his siblings. Moreover, he was sometimes unable to express himself in Arabic and finds difficulties in saying many phrases. According to Elham (his sister), our parents did not pay any attention to that "problem". The only source for practicing the heritage language was codeswitching. Elham and the father stated that Ahmed was using code switching strategies to facilitate discourse. The latter confirmed that codeswitching was nearly the solely occasion during which Ahmed was using the L2 . Ahmed reported that he found codeswitching a good tool to facilitate and alternate the two language. His fader said:

Once Ahmed was speaking to me about a number of notes he wrote to put in one paragraph. He first said in English "I like to put them in a paragraph but they do not make sense". Then he switched to Arabic and said "nabi naderihm fi mkalh bas ma make-atch sense". The last two words are English mixed with Arabic (do not $=$ atch, make and sense).

Interestingly, Ahmed reported that his parents did not support him to be an effective Arabic user. He also said that his parents made him love English and perceive it as a lingua franca being used everywhere. Ahmed went on to say he could neither read nor write in Arabic effectively while he is able to communicate in English perfectly. His parents confessed that they felt responsible for this situation. Further, they are now afraid that Ahmed may lose his Arabic as he became more proficient in English than Arabic. Regarding the loss of his ethnic identity, Ahmed's parents underestimated the effect of the L2 on losing his cultural identity, considering 
that Islam as a religion is adequate to protect his identity and language. As a result of all such actions, Ahmed tends to prefer English to Arabic.

In summary, it was explored that Ahmed parents' concern about his study resulted in imbalance in the development of the native language and the second language. Also, such an action gave Ahmed a driving force to be interested in English rather than Arabic.

\section{(Q2. What is the part that school plays in assisting the subject to acquire the first and second language?)}

Similarly, Ahmed's school (a monolingual, Australian state school) played an indispensable part in supporting his English abilities. Additionally, the scholastic environment had a profound influence on his oral and literacy proficiency. According to Ahmed, the teachers made tremendous efforts to develop his English. He always used to have supplementary classes to catch up with his classmate's level. All materials were taught in English. All of his classmates were Australian native speakers, in addition to a few Arabic and African classmates. The medium of communication when they play in school was English. As he says: English was here, there and everywhere. English became the language that I most use and hear.

Ahmed's father indicated that the teachers in school told him to interact with Ahmed in English as much as they could. In the beginning, the parents used to mix English and Arabic to help him learn English and do his homework. The English level of the materials and the medium of instruction were beyond his capabilities. However, with the passing of time, he was able to manage his school tasks himself. Ahmed said that he became excellent user of English due to the effective English environment he experienced in school. As can be seen, Ahamd's monolingual school was a great influential element in the growth of his L2.

\section{(Q3. What resources are available for the participant to acquire $L 2$ in the second language community?)}

The second language community (Australian community), where Ahmed had been living for 5 years, was a significant resource for Ahmed's L2 spoken language development. Many social sources were available for the participant to acquire and learn L2 such as school, street and social facilities. Ahmed's father reported that his son successfully integrated with the target language (TL) community as he "was warmly welcomed". His son improved his English in the school, gym, recreation centre and football pitch. The data revealed that In such places Ahmed grasped a great chance to have a constant daily contact with TL speakers (e.g. friends, acquaintances, classmates and teachers. Furthermore, it was seen that the other significant sources were the L2 community attitude and the length of residence in Australia. Both of these variables provided an efficacious environment for Ahmed to enhance the development of his L2 oral proficiency. Thus, the L2 social facilities, school, L2 group attitude, length of residency fruitful factors in the enrichment and enhancement of Ahmed's L2.

\section{(Q4. How was the child's attitude towards the two languages involved and what part did his attitude played in maintaining a $L 1$ and developing a L2?)}

Ahmed's attitudes and linguistic behaviour in regard to Arabic and English changed over time. At first, Ahmed was using Arabic and little English. However, as soon as Ahmed started school and integrated into Australian-English environment, his English progressed and took precedence over Arabic. Ahmed's father said that:

The family instilled in Ahmed the love of Arabic and the necessity of English. He really liked both languages. But, because of our excessive concern of Ahmed's study which was only in English, Ahmed became interested in English rather than Arabic.

Ahmed felt much more comfortable with using English. He also found English easier than Arabic. According to Ahmed, Arabic is a bit complex, particularly the classic language. Through the interview, Ahmed said that the spoken English as well as English literacy is much easier than Arabic. Ahmed indicated that he liked English books and TV Channels rather than Arabic ones. Surprisingly, Ahmed attributed his failure in developing Arabic literacy to the complexity of Arabic language. Now, Ahmed prefers using English in communication and integration with his friends as well as siblings.

\section{(Q5. did cultural identity help the subject to maintain L1 and was cultural identity an obstacle in acquiring} L2?)

In regard to Ahmed's group cultural identity, he stated that he is a Libyan-Arabic individual only. He considers that English is an important character in his personality, but it does not reflect his cultural and ethnic identity. Interestingly, Ahmed believes that neither English nor Arabic are a necessary component in his identity construction. He strongly consider that the religion, traditions and customs are the essential factors in preserving and reflecting ones' identity. Moreover, through the interview, Ahmed clearly pointed out that his Islamic-Arabic cultural identity was a driving force to succeed in his study but not to maintain his first language. Apprehension of loss of his ethnic identity was not a concern for Ahmed because he believed that learning L2 
and a new culture enhanced their pride in his identity and a strong affiliation to his ethnic group. To summarise, as Ahmed assumes that language is a minor part in constructing the cultural and social identity, the cultural identity was never a tool that may assist to maintain the first language or impede the L2 acquisition.

(Q6. Did the participant's minority group contribute to the maintains of the first language?)

It was reported that the participant's ethnic group in Toowoomba city, where the participant has been living, did not have any cultural facilities and activities (e.g. schools or social clubs). According to the participant's family, the absence of such important amenities and social actions created a cultural and social vacuums and forced the ethnic group members to enrol in the monolingual schools and join the TL social facilities. The participant's father said:

he was not able to send Ahmed to an ethnic school or bilingual school because there were no any ethnic school, bilingual school or even cultural activities in Toowoomba city.

In short, the ethnic group of the participant did not establish any types of cultural facilities through which its members may socialise or maintain their first language.

Table 2: A Summary of the Impact of Socio-psychological Factors on the Maintenance and Development of L1 and L2 Experienced by a Libyan Bilingual Child

\begin{tabular}{|c|c|c|}
\hline \multirow{2}{*}{ Socio-psychological Factors } & \multicolumn{2}{|c|}{ The Impact of Socio-psychological Factors on the Participant's Two Languages } \\
\cline { 2 - 3 } & The Maintenance of the L1 & The L2 Acquisition \\
\hline The role of family & Negative & positive \\
\hline Monolingual school & Negative & positive \\
\hline The L2 community & ------------- & positive \\
\hline The participant's attitude & Negative & positive \\
\hline The culture identity & Negative & No effect \\
\hline The Ethnic group & Negative & ------------- \\
\hline
\end{tabular}

\section{Discussion}

Many children have become bilingual and biliterate due to the contribution of specific sociopsychological factors. The absence of such significant elements could result into the loss of native language or imbalanced linguistic development in the both languages involved. This study threw light on the influences of particular factors on bilingual and biliteracy development of a Libyan child in Australia. Drawing upon the outcomes from the data analysis and the findings of the literature review, the influence of specific sociopsychological factors on the development and the retention of the two languages experienced by a Libyan bilingual child will be discussed.

\subsection{Discussion of the Research Questions:}

4.1.1 The role of the parents in developing the two languages involved and the sources available for the participant to maintain the heritage language.

Unquestionably, Family, particularly parents, can play a significant role in the acquisition of L2 and the retention of L1 [10]. Despite the fact that there are many obstacles through the process of maintaining the heritage language, the immigrants must always strive to maintain their native language. In this study, The results revealed that the parent's excessive concern of the participant's study made him more interested in English than Arabic. Moreover, the strategy that the parents employed at home (using English as a means of communication) resulted in fossilization in the heritage language improvement of the participant. Due to such an action, the participant's L2 (English) surpassed his first language (Arabic). This conclusion is almost in line with the claim that , in immigrant families, home is often the only place where the L1 is heard and used and the ignorance of such an action could lead to the loss or fossilization of the native language [6] \& [11]. Such a result also confirms the reference [12] claim that the home is considered as "a key element in language maintenance-if a language is not maintained in the home domain, then it cannot be maintained elsewhere".

In addition, it was reported and discovered that the only available instrument for the participants to practice the heritage language was codeswitching. The codeswitching strategy is seen by many language scholars as a linguistic tool that plays an enriching role in the retention of the L1[6]. Nevertheless, A drawn corollary of the data clearly revealed that code-switch used by the participant did have a contribution to his heritage preservation. Such a result is incompatible with the findings of the literature which hold that codeswitching can play a significant and enriching part in maintaining the heritage language [13]

\subsubsection{The significance of bilingual schools and classrooms for bilingual children.}

There is no doubt that bilingual schools have a fundamental effect on the development of the two languages involved [4]. The outcomes demonstrated that the participant's monolingual school had a great effect 
on the development of his L2 speaking and writing skills. The child was put in a monolingual immersion education programme in an elementary state school. At first, Ahmed encountered some issues in acquiring L2 and understanding some school subjects as the studying materials and the medium of instruction were greatly beyond his level. However, due to the constant contact with his classmates, supplementary classes and consultation hours, he was successfully able to overcome such problems and became proficient in both speaking and writing skills.

Indeed, such results confirmed the reference's [14] and the reference's [15] findings which reported that, linguistic norms are affected by personal relationships with TL speakers such as friends and classmates and sharing the same social facilities (e.g. schools) with the TL group can effectively promote L2 learner' chances to have a constant contact with TL speakers. The data showed that the participant learnt English only in that school even though there was a couple Arabic speaking class/schoolmates. In other words, monolingual schools are a one way street that helps to develop the second language and may lead to the loss of the home language. This conclusion is consistent with the literature that confirms the effectiveness of bilingual education in producing effective bilingual speakers and the negative impact of monolingual programmes on such a process [4].

\subsubsection{The wider linguistic community and second language development.}

As reported by the participant, English is everywhere and a lingua franca. Also, if he wants to live and work easily in that country, he must speak English. The linguistic community basically contributes to increase the participant's L2 proficiency. This result corresponds with the reference [16] and the reference [17] findings that hold that a wider linguistic community can play a significant part in improving the L2 learners more effectively.

\subsubsection{Attitudes: a key factor in development of the second language and the loss of the native one.}

There is no doubt that attitudes can affect the acquisition of the second language ( literacy and spoken language) [18]. On the negative side, attitudes can result in the loss of the heritage [2]. The participant said that English (particularly writing and reading) was much easier than Arabic. He felt more comfortable with English than Arabic. This belief, in return, results in a strong desire to learn English language. This attitude would also make him less interested in using Arabic in his everyday social activities. This conclusion affirmed the findings of literature that attitudes are a key component in initiating any L2 learning efforts [19] \& [20] and fossilizing or losing the first language [2].

\subsubsection{Group-cultural identity and the ethnic language.}

For many ethnic groups, cultural identity is basically maintained by the ethnic Language [21] \& [22]. However, in the subject's case, the group cultural identity is not a tool to preserve the native language or even reflect the social identity. Interestingly, the participant believes that that his identity is reflected by and linked to his religion and culture (traditions, customs and history). This result is nicely consistent with the reference's [23] study on the Irish ethnic group who consider the core value of Irish ethnic group is centred in the Catholic religion. Further, the loss of cultural identity was not an obstacle to the participant in acquiring the second language. On the contrary, as he indicated, his cultural identity assisted him to outperform in his study. This conclusion is relatively in line with the reference's [24] study which was conducted on cultural identities of students from ethnic minority group called Miao in China. According to the authors, the students' cultural identity played an important part in gaining high grades in schools.

\section{Conclusion}

In conclusion, the literature reported that a number of socio-psychological factors had an influence on the development of the second language and the fossilization of the heritage language . The data confirmed the findings of the literature review proposing a strong link between the socio-psychological factors and the bilingualism process. In other words, in this case study, these variables played an important role in acquiring and developing English language and fossilizing the first language. The outcomes suggested that the apprehension of child's parents about his study made the participant more interested in English (oral language and literacy) than Arabic. Consequently, his L2 surpassed his home language. Also, the use of code switching strategy used by the participant played a negative role in developing or preserving the L1 of the participant. In addition, the results indicated that the child's school and the second language community helped the participant greatly to develop the second language (Schuman, 1986 \& Hamza, 2013). The case study demonstrated that the fear of the loss of group cultural identity did not assist the child to maintain the participant's L1 as he considers that the Arabic-Libyan ethnic group's core value is not centred in Language but in the religion and culture. Further, the results suggested that the pride of the group cultural identity helped the child to outperform other students in the school. 


\section{Journal Papers:}

\section{References}

[1]. P. Ro, and G. A. Cheatham, Biliteracy and bilingual development in a second-generation Korean child: A case study, Journal of research in childhoods education, 3(23), 2009, 290-308.

[2]. E . Macaro, Codeswitching in the L2 classroom : A communication and learning strategy, Educational Linguistics, 5, $2005,63-84$.

[3]. M. Clyne, and S. Kipp, Trends and changes in home language use and shift in Australia, Journal of Multilingual and Multicultural Development, 18, 1997, 451-473.

[4]. I.D. Bois, Language attrition and code-switching among US Americans in Germany, Stellenbosch papers in linguyistics PLUSS, 39, 2009, 1-16.

[5]. J. H. Schumann, Research on the acculturation model for second language acquisition, Journal of Multilingual and Multicultural development, 5(7), 1986, 279-390.

[6]. M. Jiang, J. R. Green, B. T. Henley, and G. W. Masten, Acculturation in relation to the acquisition of a second language, Journal of Multilingual and Multicultural Development, 30(6), 2009, 481-492.

[7]. A. J . Spenader,. Language learning and acculturation: Lessons from high school and gap, year exchange students, Foreign Language Annals, 44(2), 2011, 381-398.

[8]. H. M. A. Muftah, The investigation of the possible connections between acculturation and the acquisition of a second language on Libyan teenage students, International Journal of Social Science and Engineering, 7(10), 20133, 965-980.

[9]. B. Spolksy, Bridging the gap: A general theory of second language learning, TESOL Quarterly, 22, 1988, $377-396$.

[10]. J. J. Smolicz, Core values and cultural identity, Ethnic and Racial Studies, 4(1), 1981, 75-90

\section{Books:}

[11]. C, Baker, and P.S. Jones, Encyclopaedia of bilingualism and bilingual education (Clevedon: Multilingual Matters, 1998).

[12]. F, Grosjean, Bilingual life and reality (Cambridge Mass.: Harvard University Press, 2010).

[13]. C. Baker, Foundations of bilingual education and bilingualism (Canada: Colin Baker, 2011)

[14]. C. Hoffman, An introduction to bilingualism (London: Longman, 1991).

[15]. J. R. Fraenkel, and N. E. Wallen, How to design and evaluate research in education (New York: McGraw Hill INC, 1993).

[16]. B. Johnson, and L. Christensen, Educational research: Quantitative, qualitative, and mixed method approaches (California: Sage Publications, Inc, 2008).

[17]. J.A . Fishman, Reversing language shift: Theoretical and empirical foundations of assistance to threatened languages (Clevedon: Multilingual Matters, 1991).

[18]. D. Brown, Principles of language learning and teaching (White Plains, NY: Pearson Education, 2007).

[19]. H. T. Trueba, and Y. Zou, Power in education: The case study of Miao university students and its significant for American culture (London: Falmer Press, 1994).

\section{Chapters in books:}

[20]. H. Halmari, Codeswitching patterns and developing discourse competence in L2, in D. Boxer and D. Cohen (Eds.), Studying speaking to inform second language learning (Britain: the Cronwell Press, LTD, 2004) 115-125.

[21]. Z. Dornyei, and P. Skehan ,Individual differences in 12 learning, in C. D. M. Long (Ed..), The handbook of second language acquisition (Malden, MA: Blackawell Publishing, 2003) 589-630 .

[22]. Dornyei, V. Durow, and K. Zahran, Individual differences and their effects on formulaic sequence acquisition, In N. S. (Ed.), Formulaic equences: Acquisition Processing, and Use (Amsterdam John Benjamins B.V, 2004) 87-105.

\section{Electronic papers:}

[23]. L. Hinton, Involuntary language loss among immigrants: Asian-American linguistic autobiographies. Retrieved from http://www.cal.org/resources/digest/digestpdfs/9910-hinton-langloss.pdf 